\title{
World No Tobacco Day 2018: towards a sustainable campaign involving the cardiovascular community
}

Fatimah El-Awa ${ }^{1}$, Nizal Sarrafzadegan ${ }^{2}$, Slim Slama ${ }^{1}$ and Asmus Hammerich ${ }^{1}$

'Department of Noncommunicable Diseases and Mental Health, WHO Regional Office for the Eastern Mediterranean, Cairo, Egypt. ${ }^{2}$ Isfahan Cardiovascular Research Center, Cardiovascular Research institute, Isfahan University of Medical Sciences, Isfahan, Islamic Republic of Iran.

Citation: El-Awa F; Sarrafzadegan N; Slama S; Hammerich A. World No Tobacco Day 2018: towards a sustainable campaign involving the cardiovascular community. East Mediterr Health J. 2018;24(5):409-410. https://doi.org/10.26719/2018.24.5.409

Copyright ( ) World Health Organization (WHO) 2018. Some rights reserved. This work is available under the CC BY-NC-SA 3.0 IGO license (https:// creativecommons.org/licenses/by-nc-sa/3.o/igo).

The movement to reduce tobacco use has been gathering pace in the Eastern Mediterranean Region (EMR), as governments aim at implementing legislation to encourage populations to turn away from tobacco consumption and avoid the associated health risks. Indeed, within the Region it was in 2007 that Egyptian cardiologist Prof. Hamdi El Sayed, former member of parliament and former head of the Medical Syndicate, successfully proposed legislation for the implementation of graphic health warnings on tobacco packets covering $50 \%$ of visible packaging (1). In 2011, cardiologist Dr George Saade, former focal point of tobacco control in the Lebanese Ministry of Health, proposed banning tobacco use in all public places in Lebanon - a country coined a "paradise for smokers" in local media - and witnessed the implementation of this ground-breaking legislation (2). Meanwhile, in 2013, cardiologist Dr Sania Nishtar, Pakistan, stood strongly in support of the tobacco control movement with regard to the adoption of legislation comprehensively banning tobacco advertising in Pakistan (3).

These examples and many others have been instrumental in advancing the tobacco control agenda at all levels (4). The statements of the World Congress of Cardiology and Cardiovascular Health of the World Heart Federation have, repeatedly, cited examples of the work of cardiologists in tobacco control and underlined the importance of continued efforts in this regard (5). The influence of cardiologists and the cardiovascular community on the tobacco control movement leaves no doubt that they have a remarkable and impactful role to play.

In the changing world of tobacco control there are many emerging challenges, including the introduction of new tobacco products. Thus, the role of cardiologists and the cardiovascular community is essential, noting that cardiovascular disease (CVD) is still the main cause of death in almost all EMR countries, and the fact that the Region is expected to face a dramatic rise in CVD in the next decade. Their role is needed at many levels including clinical, public health and policy, and the promotion of existing international packages in their work, such as the WHO Global HEARTS initiative (6); highlighting the role of tobacco as a major risk factor for CVD; including combatting tobacco use in clinical guidelines of every CVD type; supporting scientific research on new tobacco products; confronting misleading information from the tobacco industry; advice on tobacco use prevention and cessation; and networking with civil society entities to prioritize tobacco control.

When the RJ Reynolds Tobacco Company launched its "More Doctors" campaign in 1946, they knew that doctors' preferences and choices would influence the public, and was a blatant attempt to manipulate the element of trust between physicians and the public (7). On 31 May 2018, World No Tobacco Day (WNTD) focuses on the heart and is a chance for renewed commitment for the participation of cardiologists in the tobacco control movement. This movement has, since the entry into force of the WHO Framework Convention on Tobacco Control (FCTC) in 2005 (8), benefited greatly from the inclusion of many other disciplines. Sustaining the efforts of cardiologists and the cardiology community is essential. This can only be achieved through continued partnership with the global tobacco control movement, and establishment of sustained networks between national, regional and global cardiovascular communities in the area of tobacco control. This year, WNTD is a great opportunity to commence a new phase of stronger solidarity among all tobacco control workers, to move forward towards meeting new challenges, and to end altogether the tobacco use epidemic.

\section{References}

1. World Health Organization Regional Office for the Eastern Mediterranean (EMRO). New pictorial health warnings on tobacco products. Cairo: EMRO; 2012 (http://www.emro.who.int/egy/egypt-news/tobacco-pictorial-warnings.html).

2. Agence France Press. No butts about it, Lebanon a smoker's paradise. The Daily Star. 30 May 2009 (http://www.dailystar.com.lb/ News/Lebanon-News/2009/May-30/54987-no-butts-about-it-lebanon-a-smokers-paradise.ash, accessed 16 April 2018).

3. World health Organization. WHO to establish high-level commission on noncommunicable diseases. Geneva: World Health Organization; 2017 (http://www.who.int/mediacentre/news/statements/2017/ncd-commission/en/).

4. European Society of Cardiology. Position paper on the "tobacco products directive". Biot: European Society of Cardiology; 2013 (https://www.escardio.org/static_file/Escardio/EU-Affairs/tobacco-products-directive-position-paper.pdf). 
5. World Heart Federation. World Congress of Cardiology \& Cardiovascular Health, Mexico City, Mexico, 4-7 June 2016 (https:// www.world-heart-federation.org/global-experts-call-stronger-tobacco-control-laws-save-millions-lives-per-year/).

6. World Health Organization. Global hearts initiative. Geneva: World Health Organization; 2017 (http://www.who.int/ cardiovascular_diseases/global-hearts/en/).

7. Gardner M, Brandt AB. "The doctors' choice is America's choice" - the physician in US cigarette advertisements, 1930-1953. Am J Public Health. 2006 Feb;96(2):222-232. doi: 10.2105/AJPH.2005.066654. PMID:16434689

8. World Health Organization. WHO framework convention on tobacco control (FCTC). Geneva: World Health Organization; 2005 (http://apps.who.int/iris/bitstream/handle/10665/42811/9241591013.pdf?sequence=1). 